\title{
Large-Scale Reorganization at Multiple Levels of the Somatosensory Pathway Follows Therapeutic Amputation of the Hand in Monkeys
}

\author{
S. L. Florence and J. H. Kaas \\ Department of Psychology, Vanderbilt University, Nashville, Tennessee 37240
}

Reorganization of somatosensory cortex after peripheral nerve damage typically has been attributed to cortical plasticity. Here we provide evidence that much of the largescale cortical reorganization that occurs after a major loss of peripheral inputs reflects the sprouting or expansion of afferents from the remaining forelimb into deprived territories of the spinal cord and brainstem. We examined sensory afferent terminations in the spinal cord and brainstem, and determined the somatotopic organization of cortical area $\mathbf{3 b}$ in three adult monkeys with previous hand or forearm amputation, as veterinary treatment of forelimb injuries. In each monkey, the distribution of labeled sensory afferent terminations from the remaining parts of the forelimb was much more extensive than the normal distribution of inputs from the forelimb, and extended into portions of the dorsal horn of the spinal cord and the cuneate nucleus of the brainstem related to the amputated hand. In the same animals, tactile stimulation of the forelimb activated much of the deprived hand representation in area $3 \mathrm{~b}$ of cortex; the lateral portion of the deprived region in area $3 \mathrm{~b}$ appeared to be reactivated by inputs from the face. These data provide important new evidence that one of the mechanisms subserving large scale reorganization in cortex is a relay of topographic changes that occur subcortically. Presumably, the expanded primary sensory inputs activate postsynaptic neurons that are normally driven by inputs from the hand so that the neurons now have receptive fields on the forearm. Since the topographic representation of the body is greatly magnified in the relay to cortex, the subcortical changes can result in dramatic cortical map changes.

[Key words: plasticity, axonal sprouting, dorsal horn, dorsal column nuclei, area $3 b$, transganglionic transport]

Cortical representations of sensory surfaces reorganize after partial peripheral deactivations so that at least some of the deprived cortex comes to be activated by inputs from skin regions near the deactivated zone (reviewed by Killackey, 1989; Calford and Tweedalc, 1990; Kaas, 1991; O'Leary et al., 1994; Weinberger, 1995). The extent of the reorganization in primates typically is

\footnotetext{
Received Mar. 14, 1995; revised July 28, 1995; accepted Aug. 14, 1995.

We are grateful to Dr. Neeraj Jain, Pam Beck and Todd Picirrilli for their assistance during the mapping experiments. This work was supported by NIH Grants NICHDHD15052 and NS16446.

Correspondence should be addressed to Dr. Sherre Florence, 301 Wilson Hall, Department of Psychology, Vanderbilt University, Nashville, TN 37240. Copyright $\mathrm{C} 1995$ Society for Neuroscience $0270-6474 / 95 / 158083-13 \$ 05.00 / 0$
}

small and can be accounted for by the strengthening of existing but previously subthreshold, or "ineffective," synaptic connections (reviewed by Garraghty and Kaas, 1992). More extensive cortical changes have been reported in monkeys with long-standing deafferentation of the forelimb (Pons et al., 1991; see, however, Lund et al., 1994). Additionally, in humans with forelimb amputations, sensations referred to the missing hand during stimulation of the face or remaining arm have been taken as evidence of cortical reorganization (Ramachandran et al., 1992; Halligan et al., 1993; Ramachandran, 1993). Indeed, recent mapping studies in humans provide direct evidence that topographic reorganization occurs in somatosensory cortex after hand or forearm amputation (Elbert et al., 1994; Yang et al., 1994; Flor ct al. 1995). Given our present understanding of connections in the somatosensory system of normal primates (see Kaas and Pons, 1988), these more extensive reoganizations are too large to be explained by the potentiation of any known connections existing in normal animals. Additional mechanisms seem to be required.

In the present investigation we had the opportunity to study the organization of the cortical maps of the body in area $3 b$ of somatosensory cortex in three monkeys $1-13$ years after therapeutic amputation of the hand or forearm. Our first goal was to confirm whether amputation of the hand produces large-scale cortical reorganization in monkeys. Our second goal was to determine mechanisms responsible for any observed cortical change. Given the growing evidence for sprouting of the central terminals of primary afferents after injury (e.g., Molander et al., 1988; LaMotte et al., 1989; McMahan and Kett-While, 1991; Cameron et al., 1992; Woolf et al., 1992; Florence et al., 1993; Koerber et al., 1994), we hypothesized that new growth may occur at the level of the primary inputs from the skin. If so, intact afferents from the arm would sprout into portions of the spinal cord and cuneate nucleus of the brainstem that were formerly devoted to inputs from the hand. We evaluated the status of the primary input distribution by injecting tracers into the skin of the remaining forelimb. The results supports the hypothesis that new growth of primary afferents can mediate cortical reorganization.

\section{Materials and Methods}

The three monkeys used in this study received partial forelimb amputations as veterinary treatment of traumatic, accidental injuries. Above the wrist (i.e., hand) amputations were carried out in two monkeys: one was an owl monkey (Aotus trivirgatus) that survived 1 year after the amputation and the other was a rhesus macaque monkey (Macaca mulatta) that survived 13 years after amputation. In the third animal, a more proximal (i.e., above-the-elbow or forearm) amputation was car- 
ried out in an owl monkey that survived 3 years after amputation. All monkeys had reached sexual maturity (adulthood) prior to the amputations.

The owl monkeys were deeply anesthetized with Isoflurane gas prior to the amputation procedures. The injured region was cleansed, the skin incised and the soft tissue near the site of amputation was dissected away from underlying bone(s). Under asceptic conditions, the bone(s) and soft tissue above either the wrist (one owl monkey) or elbow joint (one owl monkey) were resected. No effort was made to identify and ligate peripheral nerves. A pad consisting of the available musculature was constructed to cover the distal end of the exposed bone(s). The musculature and skin were then sutured in separate layers and anesthesia was discontinued. Antibiotics (penicillin, approx. 10,000 U/lb., Sub.Q) and the analgesic Banamine $(1.0 \mathrm{mg} / \mathrm{kg}, \mathrm{i.m}$.) were given during the recovery period. The amputation on the macaque monkey was performed at another institution many years prior to its transfer to the present facility.

To demonstrate the distribution of the remaining peripheral nerve inputs from the injured limb to the spinal cord and brainstem, subcutaneous injections of $0.1 \%$ cholera toxin subunit B conjugated to horseradish peroxidase were made into the dorsal and ventral surfaces of the forearm or arm. During this procedure, the monkeys were anesthetized with a mixture of ketamine hydrochloride $(20 \mathrm{mg} / \mathrm{kg}, \mathrm{i} . \mathrm{m}$.) and xylazine (0.1 $\mathrm{mg} / \mathrm{kg}$, i.m.), with supplements given as needed to maintain the anesthetic state. In all cases the injections were made in bilaterally symmetrical locations. In the macaque monkey, two $15 \mu \mathrm{l}$ injections were made subdermally in both the dorsal and ventral forearm, midway between the stump and the elbow (see figurine in Fig. 1). In the case of the owl monkey with the hand amputation, one $10 \mu l$ injection was placed midway between the line of the amputation (stump) and the elbow in both the dorsal and ventral surfaces of the forelimb. In the owl monkcy with the forcarm amputation, onc $25 \mu 1$ injection was placed midway between the stump and the shoulder in both the dorsal and ventral surfaces of the arm (see figurine in Fig. 3). Care was taken to place the tracer injections at a safe distance from the skin of the amputated stump where neuromas on the severed nerves were likely to be located. Matched injections in the contralateral, intact forearm or arm were used as controls. The animals were allowed to recover from the anesthesia before returning to their home cage. After $3-4 \mathrm{~d}$, microelectrode mapping techniques were used to determine how the damaged limb was represented in area $3 \mathrm{~b}$. The monkeys were anesthetized as described above, secured in a stereotaxic headholder, and prepared for microelectrode mapping using the procedures described in detail else where (Nelson et al., 1980). Briefly, in the hemisphere contralateral to the amputation, low-impedance tungsten microelectrodes (1-2 $\mathrm{M} \Omega$ at 1 $\mathrm{kH}$ ) ) were advanced perpendicular to the surface of somatosensory cortex in the owl monkeys; in the macaque monkey where area $3 \mathrm{~b}$ is located on the posterior bank of the central sulcus, microelectrodes were advanced through cortex parallel to the surface of the posterior bank of the central sulcus. Neuronal activity was recorded during cutaneous stimulation of the forelimb, adjacent trunk and face using fine probes and camel hair brushes; high-threshold stimuli included palpation of the muscles and manipulation of the joints. No noxious stimuli were used. At each recording site, the minimal excitatory receptive field, defined as the skin area where just suprathreshold stimuli effectively evoked responses, was mapped qualitatively from multiunit activity amplified over a loudspeaker. In the owl monkeys, which do not have a central sulcus, a grid of penetrations covered the zone of cortex where the hand representation is normally located; activity was recorded from the middle layers of cortex. In the macaque monkey, responses were recorded every $300 \mu \mathrm{m}$ while the electrode was advanced $7-9 \mathrm{~mm}$ into the posterior bank of the central sulcus in the region where the hand is normally represented (i.e., medial to the tip of the intraparietal sulcus). The location of each penetration was marked on enlarged photographs of the cortical surface. At each recording site, notes were taken of the overall level of background activity, of receptive field size and position, and of neuronal response properties. Receptive field sizes and locations were also documented on detailed drawings of the body surface. In order to avoid experimenter bias, the investigator who was mapping the receptive field was unaware of the location of the electrode. At selected recording sites, microlesions were made for later verification of the location of the recording electrode relative to cortical architecture.

After completion of the cortical mapping, each animal was given an overdose of sodium pentobarbital and perfused through the heart with a saline rinse followed by fixative ( $2-3 \%$ paraformaldehyde). Small pins were placed in identified cervical segments of the spinal cord for identification of the segmental level of transported label. The brainstem and cervical spinal cord were removed, immersed overnight in a solution of $30 \%$ sucrose in phosphate buffer $(0.1 \mathrm{M}, \mathrm{pH} 7.4)$, then frozen and sectioned on a sliding microtome. Brainstems were cut in the coronal plane, and spinal cords were cut in the horizontal plane (parallel to the dorsal surface). Every other section through the brainstem and every spinal cord section was reacted with tetramethyl benzedine (TMB) using a modification of the method described by Gibson et al. (1984) to visualize the transported HRP conjugate. The remaining brainstem sections were processed for the metabolic marker, cytochrome oxidase (CO), to assess the effects of the amputation on the pattern of CO-dense regions in the cuneate nucleus that normally reflect somatotopy of the forelimb (Florence et al., 1991).

The mapped region of area $3 b$ was removed and sectioned parallel to the electrode penetrations in a plane rotated about $30^{\circ}$ from the parasagittal plane toward horizontal. Every section through the mapped region was mounted on glass slides and Nissl-stained with cresyl violet for cell bodies. To construct cortical maps in owl monkeys, the locations of all the recording sites were plotted on a drawing of a dorsolateral view of somatosensory cortex. To reconstruct the cortical map in the macaque, each penetration was reconstructed from serial sections and plotted on a drawing of a parasagittal section of the postcentral sulcus. These drawings were entered into an image analysis system ( $R \& M$ Biometrics, Nashville, TN) to generate a rotated, three-dimensional, "en face" view of area $3 b$. Receptive fields at each recording site in layer IV of area $3 \mathrm{~b}$ were plotted on the reconstruction of area $3 \mathrm{~b}$ to produce summary maps of the forelimb representation.

\section{Results}

\section{Spinal cord}

In all monkeys, subdermal injections of the tracer in the amputated forelimb produced more broadly distributed zones of label in the dorsal horn of the spinal cord than matched injections in the normal forelimb. The projections from the normal forearm in the macaque and owl monkey formed a narrow crescent from about cervical segment 3 (C3) to $\mathrm{C} 7$ (e.g., Fig. 1). Between $\mathrm{C} 4$ and $\mathrm{C} 6$, the projections were lateral in the dorsal horn, but assumed progressively more medial positions at the rostral and caudal extremes of the labeled zones (Figs. 1, 2). Multiple injections distributed across both the dorsal and ventral surfaces of the forearm, resulted in multiple narrow foci of label separaled rostrocaudally from each other (Fig. 1). The extert and pattern of label closely corresponded to that expected from a study of the normal pattern of inputs from the skin of the forearm and hand in macaque monkeys (Brown et al., 1989; Florence et al., 1989).

The projection from the normal arm in the owl monkey seems to parallel the projection from the forearm. A rostral zone of label extended from $\mathrm{C} 2$ to about $\mathrm{C} 4$, and a caudal zone of label extended from about C7 nearly to C9 (Fig. 3). The location of label shifted from medial to lateral between $\mathrm{C} 2$ and $\mathrm{C} 4$ and then from lateral to medial between $\mathrm{C} 7$ and $\mathrm{C} 9$. Between these rostral and caudal areas on the control side no label was found.

The labeled projections after amputation of either the hand or forearm were within the appropriate rostrocaudal domains of the cervical spinal cord, but the distribution of label was more extensive on the side of the amputation compared to the controls (Figs. 1-3). In the monkeys with hand amputations, the densest zone of label was in a similar mediolateral location as label from the normal forearm; however, light lahel spanned much of the width of the dorsal horn (Figs. 1,2). This was particularly evident between about C5 and C6 where light label extended beyond the appropriate lateral location into more medial portions of the dorsal horn (Fig. 2), where inputs from the hand normally are located (Brown et al., 1989; Florence et al., 1989). In the owl monkey that had a forearm amputation, the mediolateral 


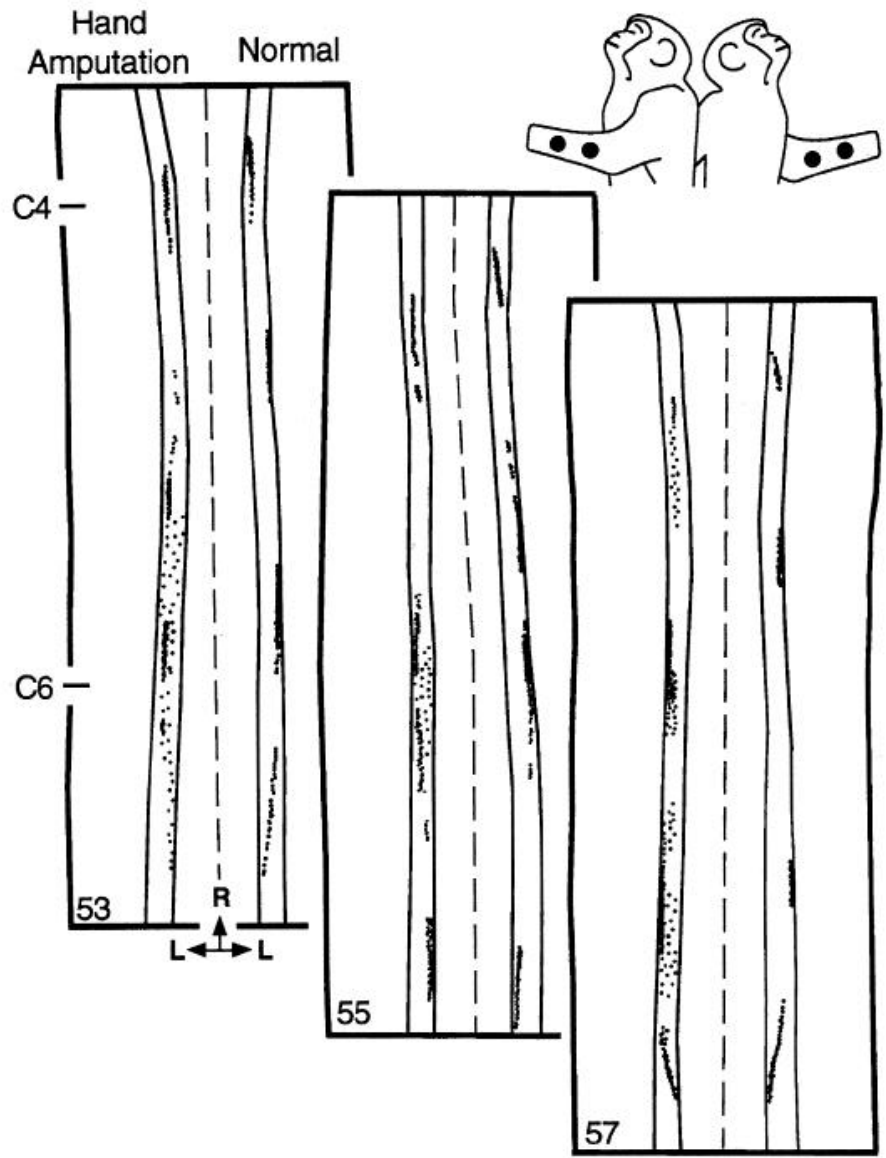

Figure 1. Pattern of label in the dorsal horn of the spinal cord after bilateral injections of cholera toxin subunit B conjugated to HRP of the forearm in the macaque monkey with amputation of the hand. The figurines depict the number and locations of the tracer injections. Only the amputated arm has been shown; however, matched injections were made into both arms. The three horizontal sections through the cervical dorsal horn form a dorsoventral sequence; progressively more dorsal sections have higher section numbers. Labeled afferent terminations are indicated by the small dots. The approximate centers of cervical segments 4 (C4) and 6 (C6) are indicated. Dashed line indicates the midline. L, Lateral; $R$, rostral.

distribution of label was only slightly more widespread than the normal projection, but a more striking difference was in the rostrocaudal extent of label. As shown in Figure 3, label from the rostral projection zone extended caudal-ward, beyond $\mathrm{C} 4$, into the segment where inputs from the forearm are normally situated, and label from the caudal projection zone extended rostrally into the zone that normally receives projections from the forearm.

After amputation of either the hand or forearm, the morphological appearance of the dorsal horn was not markedly abnormal There appeared to be a slight reduction in the width of the cervical dorsal horn, particularly in the owl monkey with forearm amputation (Fig. 3), but the effect was not nearly as dramatic as expected given that at least some of the dorsal root ganglion (DRG) neurons die as a result of the injury (A. G. Liss, F. W. af Ekenstam, and M. Wiberg, unpublished observations).

\section{Cuneate nucleus}

In all the monkeys, injections into the forearm or arm of the amputated limb labeled more extensive portions of the cuneate

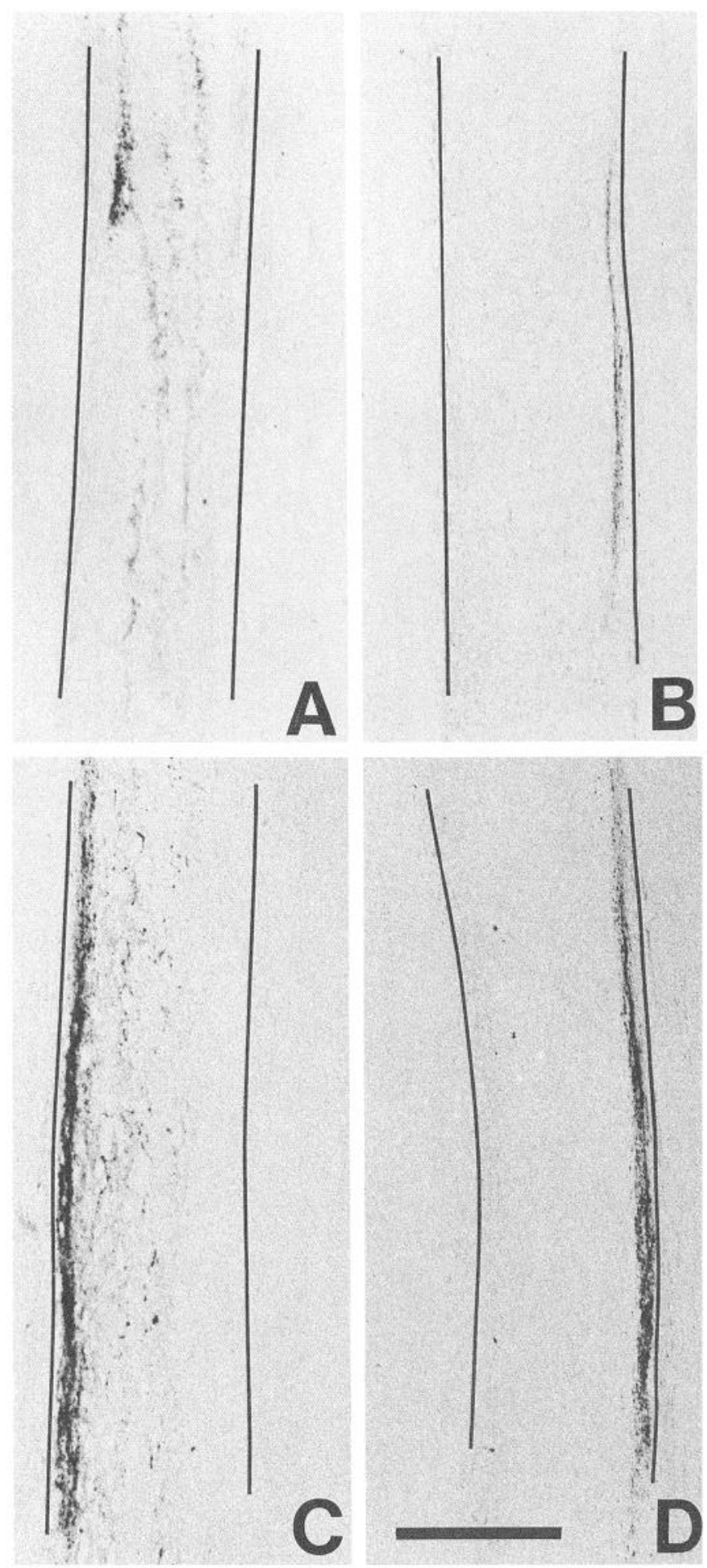

Figure 2. Photomicrographs of label in the dorsal horn after injections of cholera toxin subunit B conjugated to HRP into the normal forearm $(B, D)$ and in the forearm with a hand amputation $(A, C) . A$ and $B$ are from the owl monkey; in this animal $10 \mu \mathrm{l}$ injections were into both the dorsal and ventral surfaces of each forearm, midway between the elbow and wrist. $C$ and $D$ are from the macaque monkey; the number and locations of injections are illustrated for this animal in Figure 1. The photomicrographs are taken near cervical levels C5 and C6 where the labeled projections from the forearm normally terminate laterally in the dorsal horn as shown after injections of the normal forearms $(B, D)$. After amputation of the hand in both monkeys, light label extends medial into the deprived portion of the dorsal horn where inputs from the hand normally terminate. Solid lines indicate the borders of the dorsal horn. Scale bar, $0.5 \mathrm{~mm}$. Rostral, toward top; medial, toward center. 


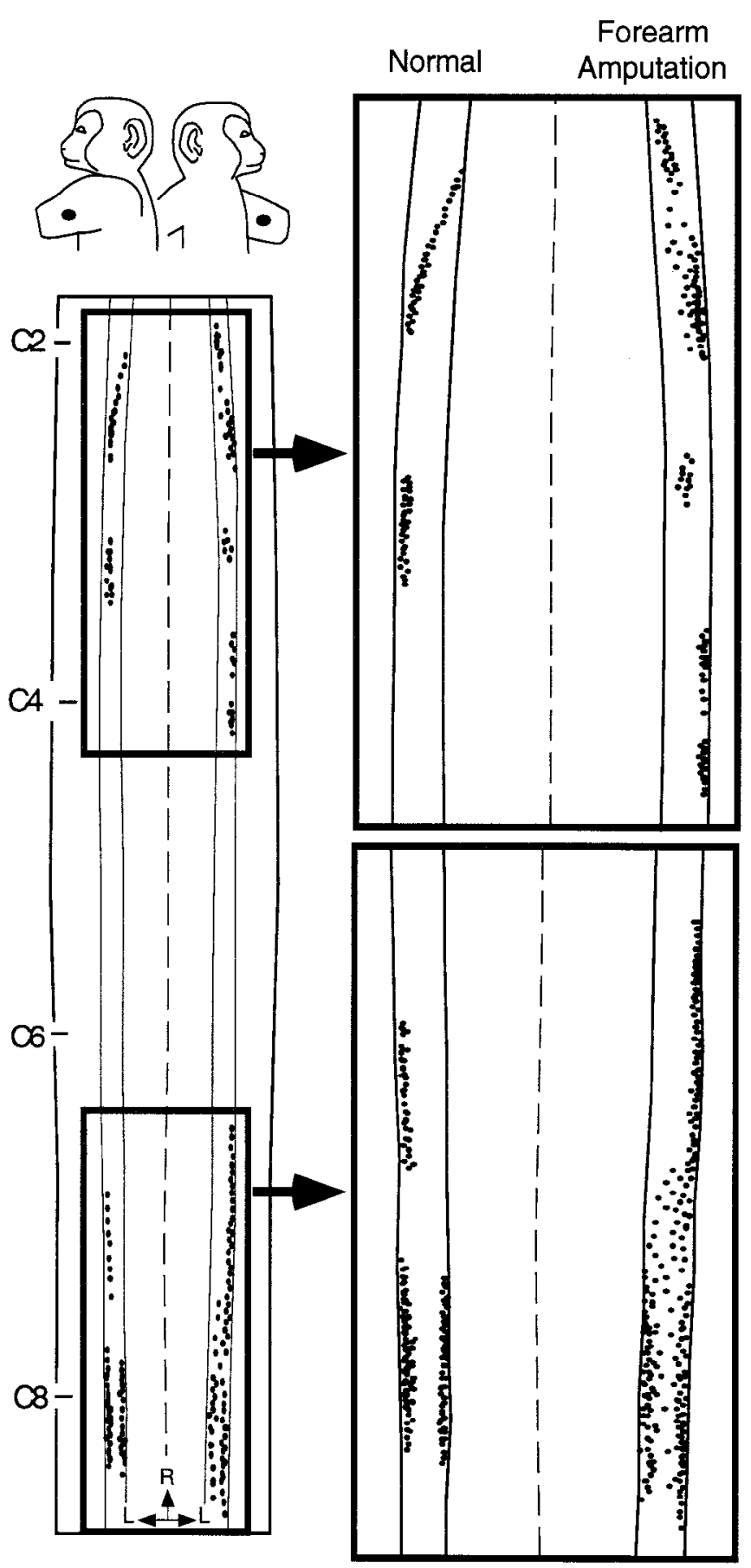

Figure 3. Line drawings of the distribution of label in the dorsal horn of the spinal cord after bilateral upper arm injections of cholera toxin subunit B conjugated to IIRP in the owl monkey with forearm (abovethe-elbow) amputation. The figurines depict the number and locations of the tracer injections. Only the amputated arm has been shown; however, matched injections were made into both arms. The line drawing on the left is a schematic of a horizontal section through the cervical dorsal horn summarizing the extent of label from all labeled sections. The panels to the right are enlargements of the rostral (upper, right) and caudal (lower, right) labeled regions. The enlargements are scaled more in the mediolateral width than rostrocaudally, so that the differences in the distribution of label on the normal (left) and amputated (right) sides can be illustrated. The approximate centers of cervical segments $2,4,6$, and 8 are indicated.

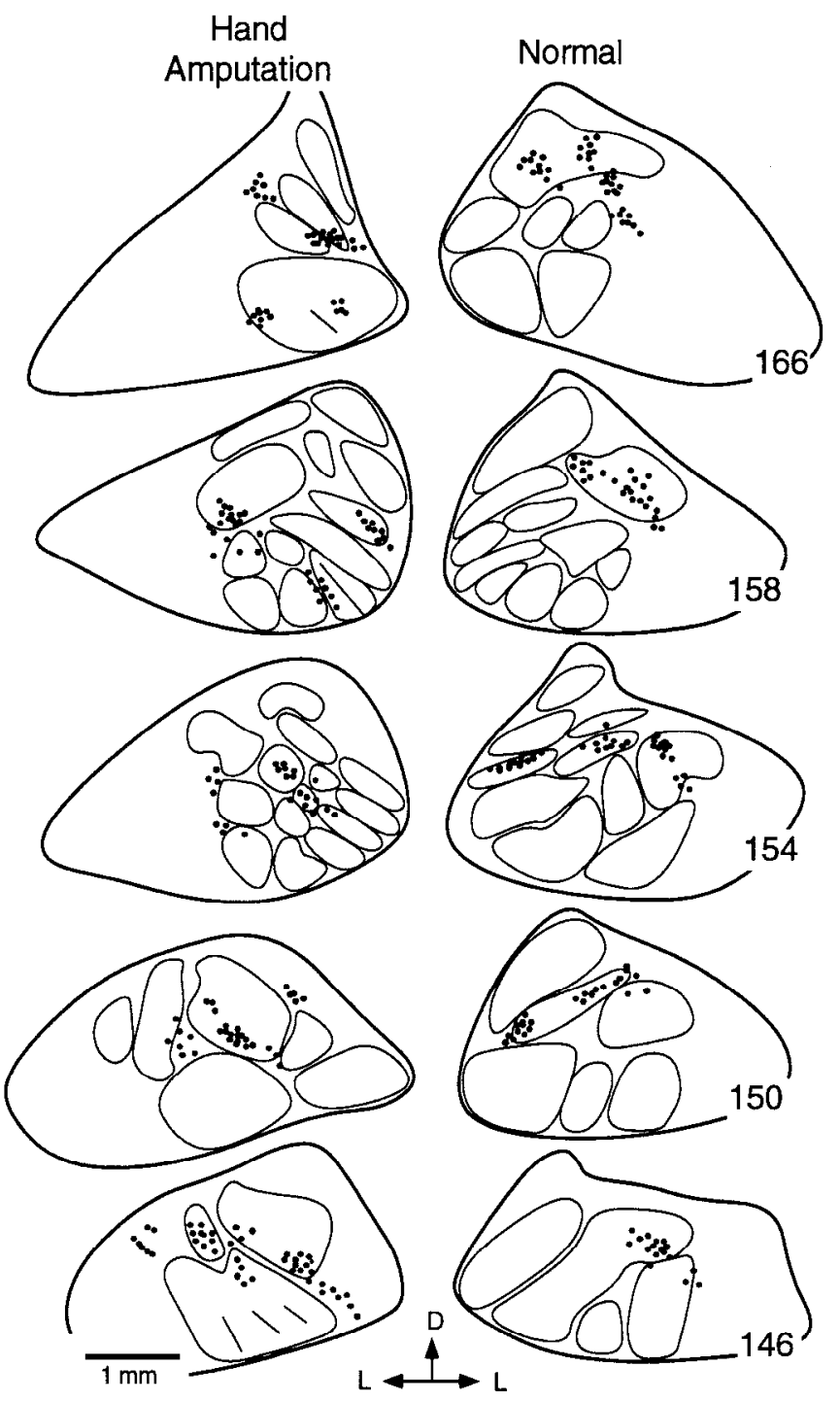

Figure 4. Line drawings of the distribution of label in the pars rotunda of the cuneate nucleus after matched injections into the forearm, on the side with a hand amputation (left panel) and on the normal side (right panel) in the macaque monkey. The number and locations of injections are illustrated in the figurines in Figure 1. The paired cuneate nuclei are from a rostrocaudal series of frontal sections; the more rostral sections have progressively higher section numbers. The outlined regions within the nucleus depict CO-dense cell clusters. Black dots indicate anterogradc labcl. $D$, Dorsal; $L$, lateral.

nucleus than matched injections in the normal limb. The projections to the cuneate nucleus were most dense in the pars rotunda (Figs. 4-6); in the rostral and caudal poles of the cuneate nucleus the label was much more sparse and is not described further in the present report. No label was found in the pars triangularis in normal animals. Labeled projections to the pars rotunda from the normal forearm terminated in the dorsal portion of the subnucleus (Fig. 4). The location of the label varied from section to section due to the progressive rotation of the orientation of the forelimb representation; however, the label did not extend into the region where the hand inputs are normally located (e.g., Culberson and Brushart, 1989; Florence et al., 1989). For example, caudally in the pars rotunda some of the inputs from the forearm were located approximately midway between the dorsal and ventral borders of the pars rotunda and extended across the 


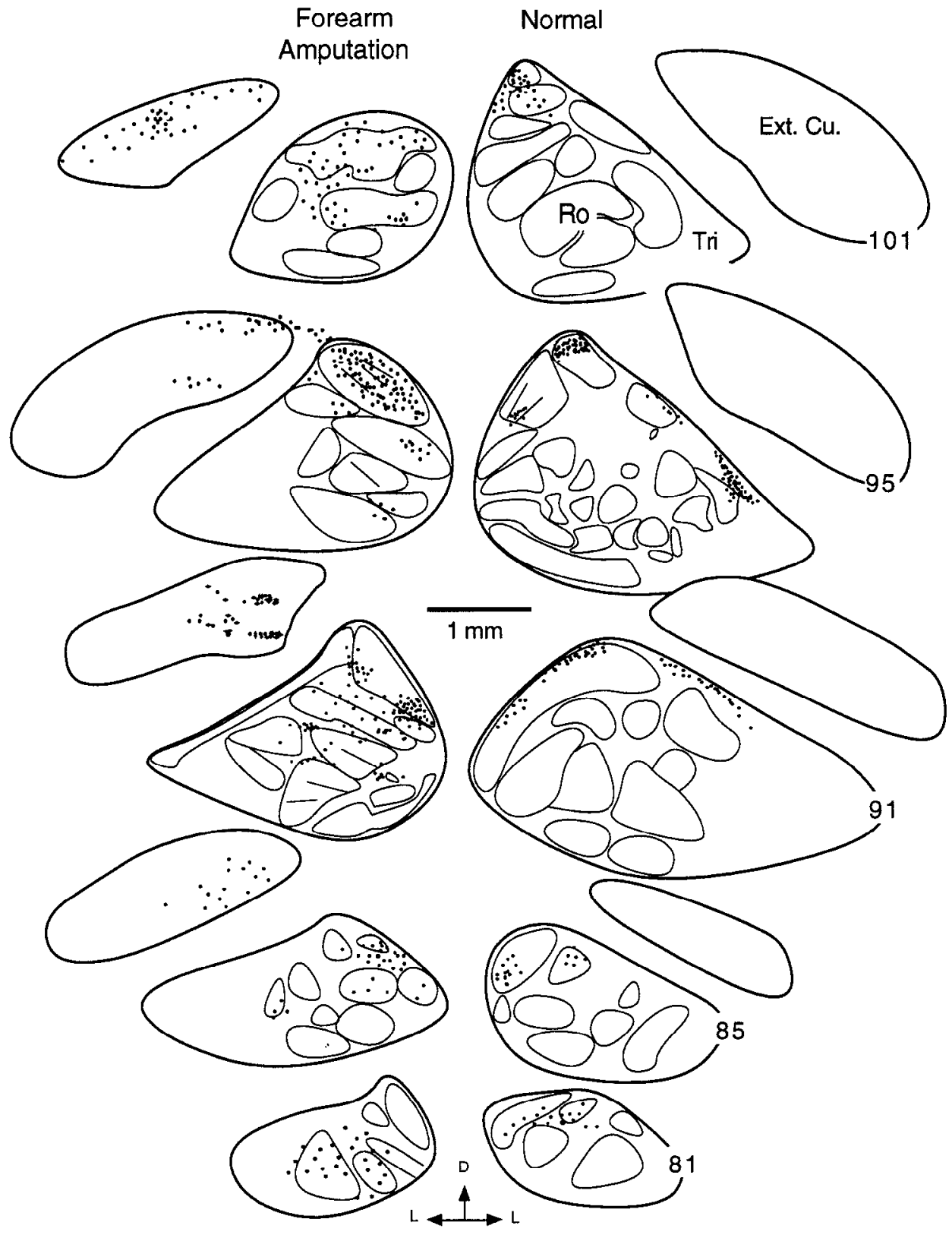

Figure 5. Line drawings of the distribution of label in the pars rotunda of the cuneate after matched injections into the upper arm, on the side with a forearm amputation (left) and on the normal side (right) in the owl monkey. The number and locations of injections are illustrated in the figurines in Figure 3 . The paired cuneate nuclei are from a rostrocaudal series of frontal sections; the more rostral sections have progressively higher section numbers. Black dots indicate anterograde label. $D$, Dorsal; Ext. Cu., external cuneate nucleus; $L$, lateral; Ro, pars rotunda of the cuneate nucleus; Tri, pars triangularis of the cuneate nucleus. entire mediolateral extent (see Fig. 4, sections 150 and 154). At this level, the inputs from hand are ventral (e.g., Florence et al., 1989). In more rostral portions of the pars rotunda, the inputs from the forearm assumed a dorsolateral position (Fig. 4, sections 158-166); at this same level, inputs from the hand occupy a ventromedial location (e.g., Florence et al., 1989). A composite of the total extent of labeling across all sections in the pars rotunda indicated that the labeling forms an arc that borders the hand representation dorsolaterally and dorsomedially. Typically, the label was concentrated within cytochrome oxidase dense clusters of neurons, although sparse label was found in the COlight regions between labeled clusters (Fig. 4).

Injections into the skin of the normal arm in the owl monkey labeled the dorsomedial and dorsolateral extremes of the pars rotunda (Figs. 5, 6). A composite of the total extent of labeling across sections indicated that the inputs from the arm forms a crescent just external to the inputs from the forearm. At the caudal extreme of the nucleus, near the border between the pars rotunda and the caudal pole of the cuneate nucleus where inputs become more dispersed, the label was located near the middle of the nucleus (Fig. 5), and may have overlapped the inputs from forearm. While there was a tendency for the projections to concentrate in $\mathrm{CO}$ dense clusters, the dorsolateral label occasionally did not relate to a region of dark $\mathrm{CO}$ staining (e.g., Fig. 6).

In the monkeys that had hand amputations, injections of the forearm proximal to the amputation densely labeled the middle and dorsal portions of the pars rotunda where forearm inputs normally project; however, labeled terminals also were located more ventrally (Fig. 4). In individual sections, this ventral label was sparse and tended to have a patchy appearance; the label extended across $\mathrm{CO}$-dense cell clusters and $\mathrm{CO}$-light, cell-free zones. Composite drawings of the distribution of label through all TMB-labeled sections indicated that labeled inputs occupied much of the ventral portion of the pars rotunda, where inputs from the hand terminate in normal animals (Culberson and Brushart, 1989; Florence et al., 1989). 

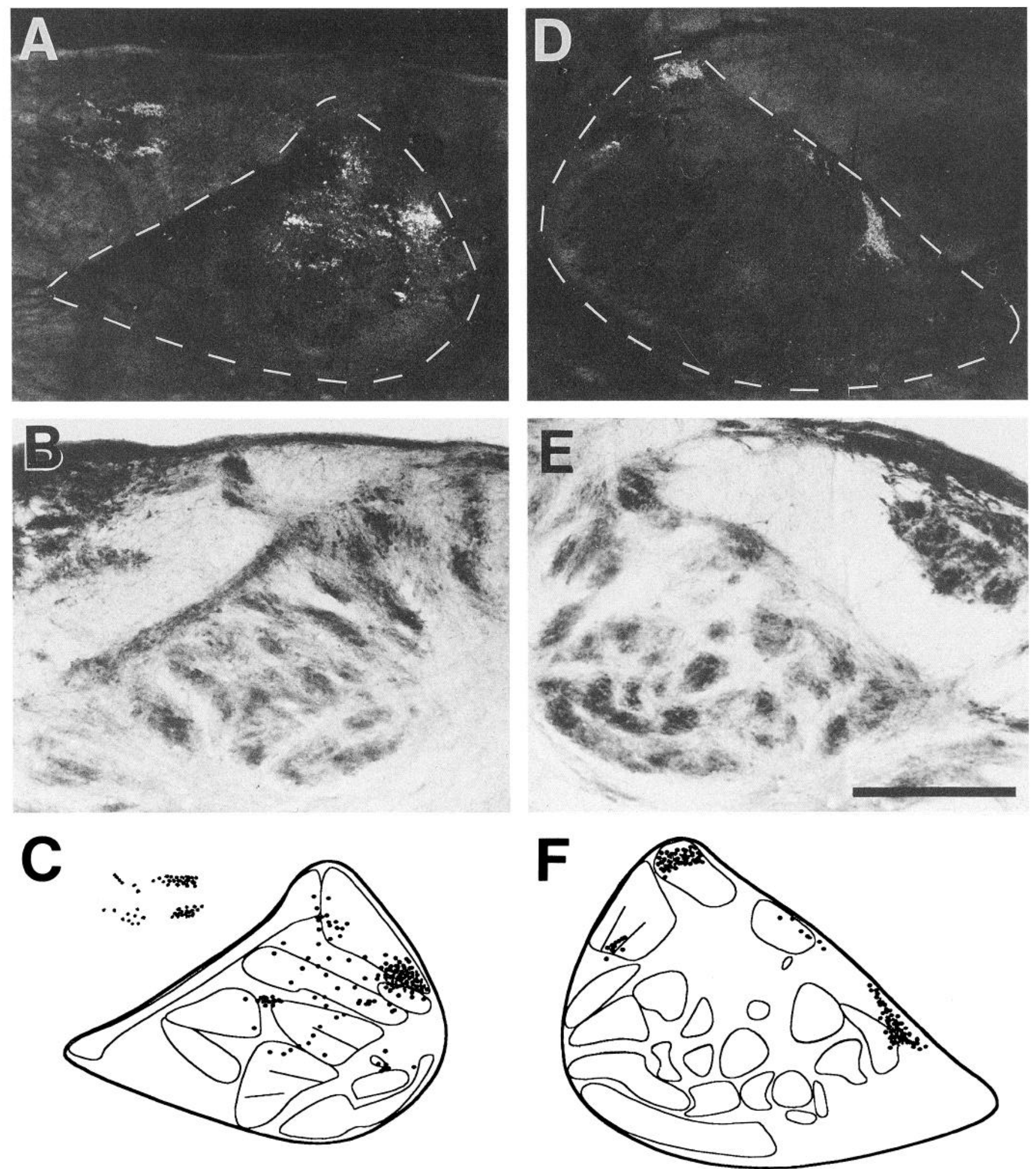

Figure 6. Pattern of label in the pars rotunda of the cuneate nucleus after matched bilateral injections of cholera toxin subunit B conjugated to HRP into the upper arm of the owl monkey after left forearm amputation. The dark-field photomicrograph shown in $A$ demonstrates the distribution of label after forearm amputation, and $D$ shows the normal pattern of label. The appearance and intensity of CO staining in the pars rotunda on the side of the amputation is shown in $B$ and on the normal side in $E$. The ventromedial portion of the cuneate nucleus which normally receives inputs from the hand does not appear to be less intensely stained for $\mathrm{CO}$ on the side of the amputation than normal, and the arrangement of COdense cell clusters is comparable to normal. Line drawings of the distribution of label in relationship to the arrangement of CO-dense cell clusters on the amputated and normal sides are shown in $C$ and $F$, respectively. Scale bar, $0.5 \mathrm{~mm}$. 
In the monkey that had a forearm amputation, injections of the arm proximal to the amputation densely labeled the dorsomedial and dorsolateral extremes of the nucleus, where inputs from the arm are normally located (Figs. 5, 6). Additionally, light label was scattered throughout the ventral portion of the nucleus (Figs. 5, 6). A composite drawing of the distribution of all the label indicated that labeled inputs occupied much of the ventral portion of the pars rotunda, spanning the zone where inputs from the hand normally terminate. In this monkey, there was sparse label in the external cuneate nucleus on the side of the amputation (Figs. 5, 6); typically the external cuneate nucleus receives inputs from the forelimb and cervical axial musculature (e.g., Nyberg and Blomqvist, 1984; Bakker et al., 1985; Hummelsheim et al., 1985), and is not labeled after skin injections in normal animals, nor in the monkeys with hand amputation.

The amputations had relatively modest effects on the morphology of the cuneate nucleus. After amputation of the hand, the overall size of the nucleus was qualitatively the same as on the control side; however, the size of the pars rotunda appeared to be slightly reduced (Fig. 4). After amputation of the forearm, the entire nucleus was smaller than on the control side (Fig. 5). However, in all cases, the density of $\mathrm{CO}$ staining in the pars rotunda was equally as dark on the experimental and control sides (Fig. 6), and there did not appear to a loss of the number of CO-dense clusters (Fig. 6). Thus, the CO-dense clusters continue to indicate the topography of the normal forelimb, long after the amputation.

\section{Area $3 b$}

In the amputated animals, in the region of area $3 \mathrm{~b}$ where the hand representation is normally located, neurons at the majority of recording sites responded briskly to cutancous stimulation of the remaining upper extremity (Figs. 7, 9, 10). After hand amputation in the owl monkey, $81 \%$ (42 of 52) of the recording sites in the expanded forearm representation responded to light cutaneous stimulation, predominantly hair displacements, and in the macaque monkey, 63\% (53 of 84 ) of the recording sites in the expanded forearm representation responded to either hair displacements or light touch. After forearm amputation, 77\% (17 of 22) of the recording sites in the expanded arm representation in area $3 \mathrm{~b}$ responded either to hair displacements or to light touch. There were no subjective differences in the magnitude or temporal pattern of responses of neurons in cortex related to the expanded forelimb representations. In all monkeys, neurons that did not respond to light cutaneous stimulation often could be activated by more intense stimulation, such as strokes or taps of the forearm or arm. In the macaque monkey in the deepest portions of the central sulcus, the electrode passed from the post central bank into the pre-central cortex (not shown), so receptive fields for the anterior part of the map were not mapped (Fig. 8).

In the portion of area $3 \mathrm{~b}$ where the hand is normally represented, the majority of cutaneous receptive fields were located on the distal aspect of the forearm or arm, near the line of amputation (Figs. 7-10), but were not located directly on the face of the amputated stump. There may have been a reduction in the size of receptive fields, particularly in the area directly adjacent to site of the amputation. This is most apparent in the owl monkey with forearm amputation (Fig. 10). In this animal, receptive fields in the medial portion of the expanded arm representation, where the arm normally is represented, were comparable in size to receptive fields located on the arm of normal monkeys. In contrast, laterally in the reorganized cortex, receptive fields were smaller (Fig. 10). Similarly in the macaque monkey with hand amputation, receptive fields nearest the amputated stump after hand amputation appeared to be smaller than receptive fields more proximal on the forearm (Fig. 7); however, reductions in receptive field size were not distinct in the owl monkey with hand amputation (Fig. 9). There appeared to be orderly representations of the dorsal and ventral surfaces of the forearm and arm. In the macaque monkey within the enlarged representation of the distal forearm in area $3 b$, the dorsal surface was represented medially and the ventral forearm laterally (Fig. 7). In the owl monkey with a hand amputation, the majority of receptive fields on the ventral forearm were located medially in area $3 b$, while receptive fields on the dorsal forearm were more numerous laterally (Fig. 9). Another pattern was found in the owl monkey with a forearm amputation. In this monkey, receptive fields on the ventral arm were clustered in the rostral portion of area $3 \mathrm{~b}$ and those on the dorsal arm were located caudally (Fig. 10). Thus, a somatotopic order tends to emerge in the reorganized cortex, but the orientation of the pattern is variable across animals.

In all monkeys, there appeared to be a reduction of the overall size of the cortical forelimb representation. In the macaque monkey with the hand amputation, the distance between arm and face representations in area $3 \mathrm{~b}$ was about $5 \mathrm{~mm}$, and in normal macaques this distance typically is about $10 \mathrm{~mm}$ (Nelson et al., 1980). Additionally, the border between the hand and face representations typically is located near the tip of the intraparietal sulcus in normal macaque monkeys, while in the macaque monkey with the hand amputation, the border of the face representation was located about $1.5 \mathrm{~mm}$ medial to the tip of the intraparietal sulcus. A similar change in the mediolateral extent of the forclimb representation in area $3 b$ was apparent in both owl monkeys. In the owl monkey with the hand amputation, the distance between the representations of the arm and face was about $4 \mathrm{~mm}$ mediolaterally (Fig. 9); in normal owl monkeys, the distance between these two borders is typically about $5 \mathrm{~mm}$ (Merzenich et al., 1978). In the owl monkey with a forearm amputation, the distance between the representations of the chest/neck area and the face was approxinately 5 minl (Fig. 10), and in normal animals these borders are separated by about $6 \mathrm{~mm}$ (Merzenich et al., 1978). These data indicate that the cortical reactivation may involve a partial takeover of deprived forelimb cortex by the face representation.

\section{Discussion}

Adult amputation results in an apparent enlargement of the afferent projections in the spinal cord and brainstem

One potential explanation for the expanded distribution of labeling is that the injected tracer labeled axons in the transected nerves at the amputated stump. We do not consider this a tenable possibility for two reasons. First, the injections were placed well away from the tip of the stump so as to avoid spread of the injected tracer to the site of the injury. Second, the distribution of transported label is not what would be expected if the tracer had invaded the peripheral neuromas, or if the tracer had been taken up by axons in the transected nerves that regenerated into the skin of the stump. If either had occurred, the label would be concentrated in the regions where inputs from the digits normally terminate (medial portions of the spinal cord and ventral portion of the cuneate nucleus), since the vast majority of axons in the transected nerves project to the digits. Instead, in all three 


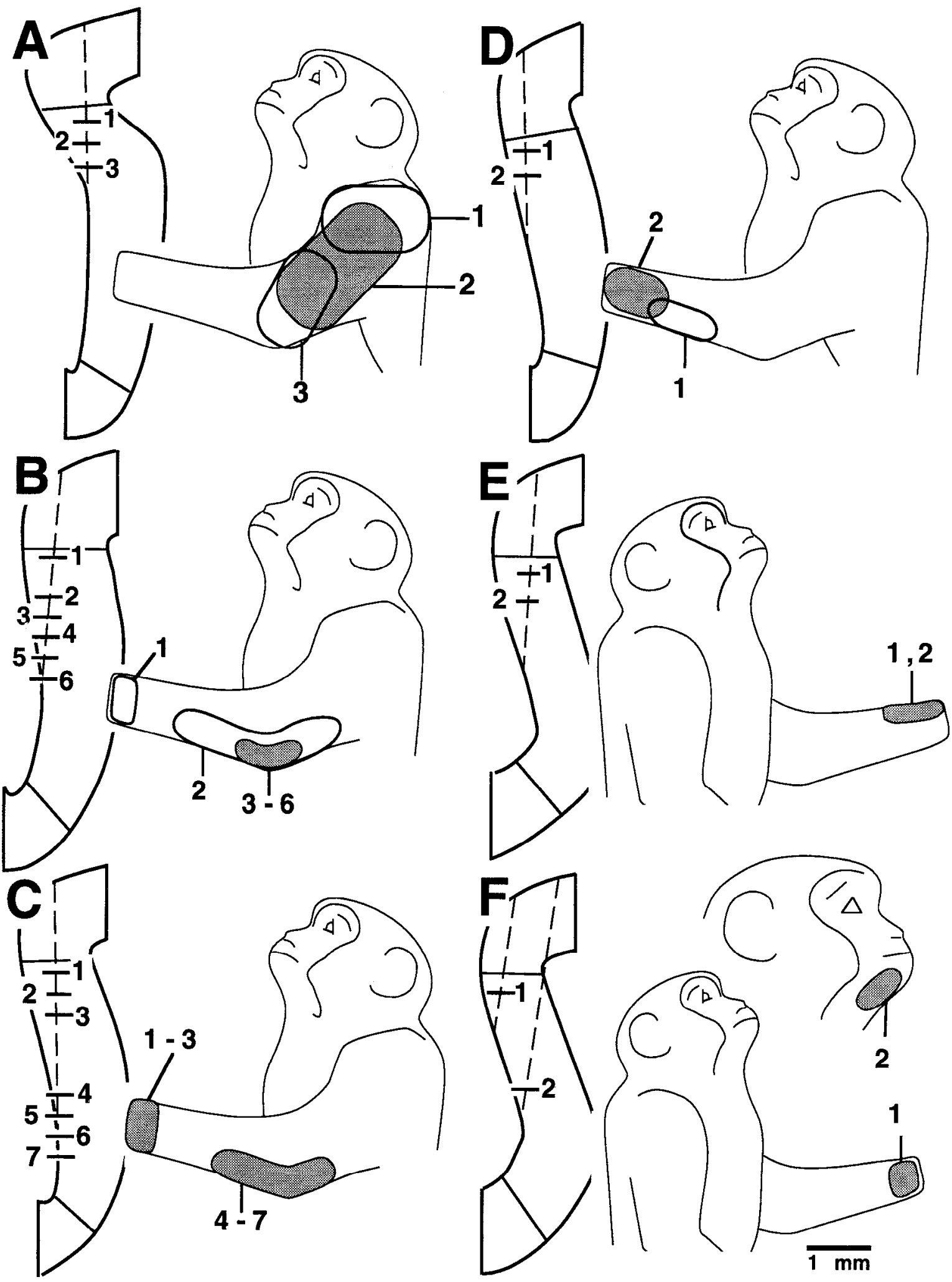

Figure 7. Cutaneous receptive fields determined from recordings in the forelimb representation of area $3 \mathrm{~b}$ in the macaque monkey with hand amputation. As indicated on the drawings of parasagittal brain sections, electrodes passed through area $3 \mathrm{~b}$, tangential to the cortical layers. Receptive field numbers on the figurines refer to numbered recording sites along the electrode track in the accompanying parasagittal section. $A-F$ represent a respective medial to lateral sequence of electrode tracks. 


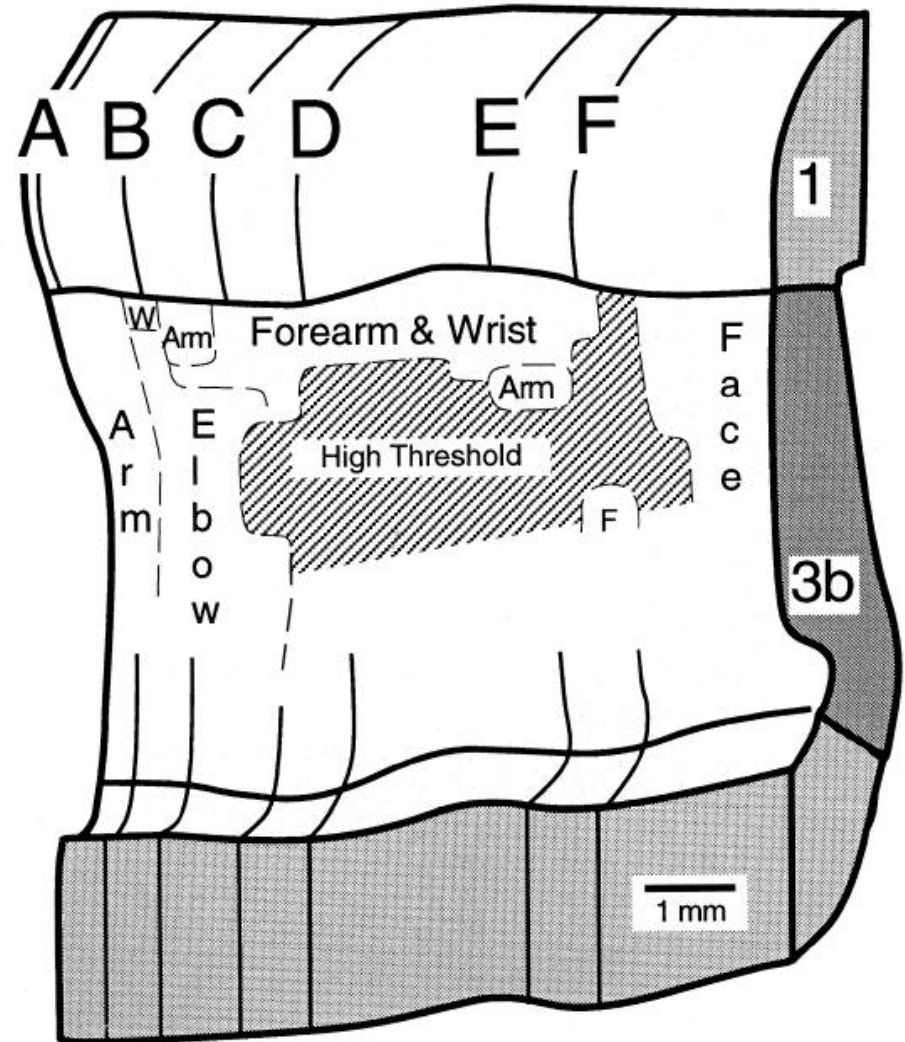

Figure 8. The topographic organization of cutaneous inputs to the forelimb representation in area $3 \mathrm{~b}$ of the macaque monkey with a hand amputation. The map is shown on a reconstructed view of the posterior bank of the central sulcus, with $A-F$ depicting the relative mediolateral position of the parasagittal sections illustrated in Figure 7. Regions of the forelimb or face where responses were elicited by cutaneous stimulation are indicated. The stippled area indicates the region where neurons were activated by high threshold stimulation, such as taps or strokes to large regions of skin. In the deepest portions of the central sulcus, the electrode passed from the post-central bank into the precentral cortex (see Fig. 7), so receptive fields for this region were not mapped. $F$, face; $W$, wrist.

animals, the expanded zone of labeling consistently was found in the deprived zone directly adjacent to the more densely labeled representation of the intact skin. Only small pockets of label were found further from the dense focus of labeled inputs in the representations of the digits. Thus, the altered labeling is unlikely to reflect inadvertent uptake of the tracer by previously sectioned nerves.

A second potential explanation for these results is that the additional label results from strengthening of existing, normally undetected, off-focus inputs (reviewed by Wall, 1977; Devor, 1983; Snow and Wilson, 1991). In the dorsal horn of the spinal cord and the dorsal column nuclei, receptive fields become enlarged or emerge in new locations after peripheral denervations and local anesthesia by nerve injections (e.g., Basbaum and Wall, 1976; Dostrovsky et al., 1976; Millar et al., 1976; Devor and Wall, 1978, 1981; Pettit and Schwark, 1993; see, however, Pubols and Benowitz, 1981; Brown et al., 1984; Wilson, 1987). The time course of these changes is variable, but at least some occur rapidly and have been interpreted as expressions of previously existing but undetected connections. However, these changes typically are more limited in extent than those that appear in area $3 \mathrm{~b}$ in the present cases. Furthermore, studies of the

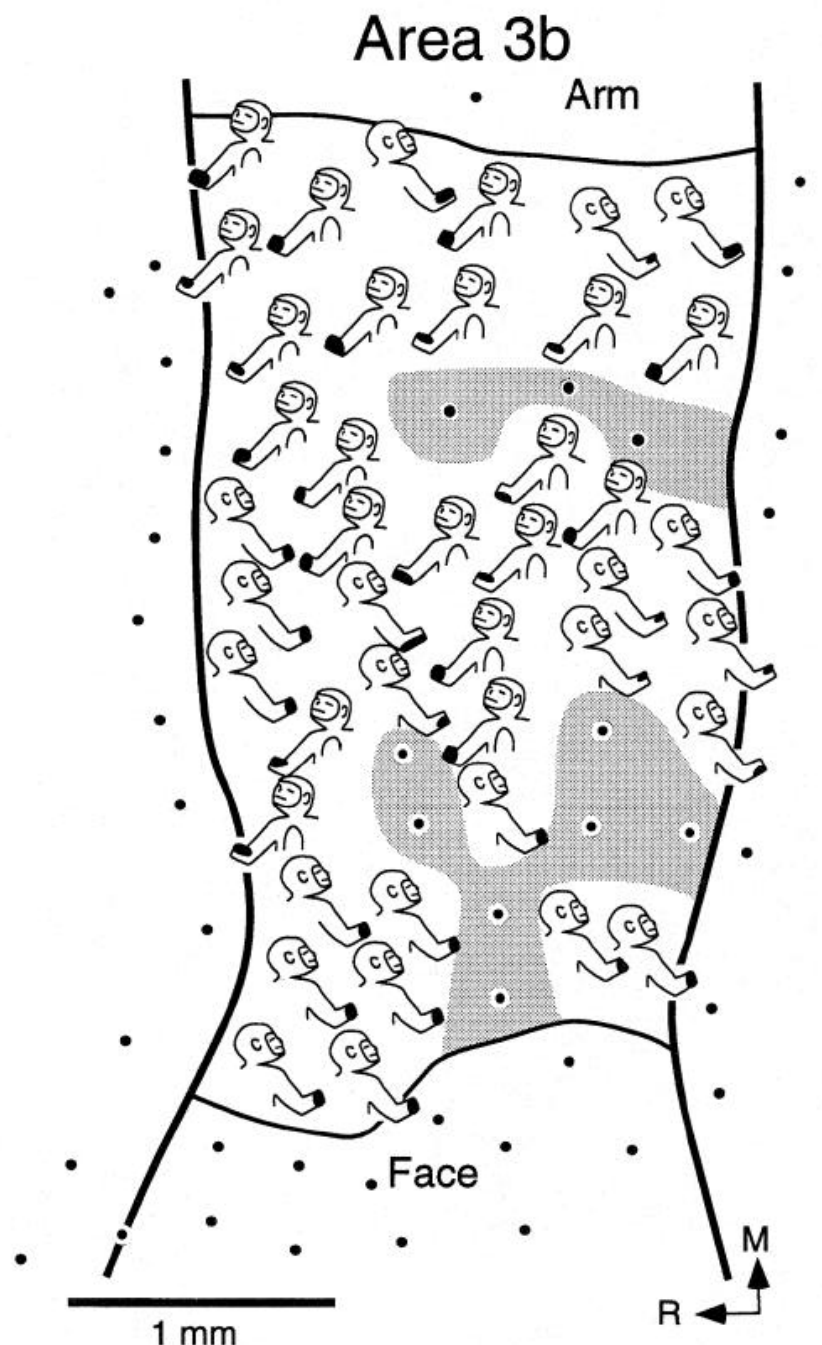

Figure 9. Dorsal view reconstruction of the topographic representation of the forelimb contralateral to amputation of the hand in an adult owl monkey. Thick solid lines depict the rostral and caudal borders of area $3 \mathrm{~b}$, and solid lines within area $3 \mathrm{~b}$ demarcate the borders between the face and forearm (bottom) and the forearm and arm (top). Each recording site is indicated by a figurine of the torso of a monkey, with the receptive field at that site shown in black. The dots rostral and caudal to area $3 \mathrm{~b}$ depict recording sites where responses either were not evoked by cutaneous stimulation (typically rostral to area $3 \mathrm{~b}$ ) or where topographic reversals indicated that the electrode had crossed cortical borders. Stippled regions indicate zones in area $3 \mathrm{~b}$ where neurons were not activated by cutaneous stimulation. $M$, Medial; $R$, rostral.

termination patterns of individual afferent axons indicate limited overlap of afferent connections. For example, Myers and Snow (1984) and Shortland et al. (1989) report in cats and in rats, respectively, that there is only moderate overlap among primary afferents from nearby hindlimb skin regions in the dorsal horn. Brown et al. (1991) and Woolf (1987) conclude that there is considerable somatotopic precision in the afferent terminations from the hindlimb to the dorsal horn of cats and rats, respectively, so that overlap of inputs from different skin regions is likely very limited. Thus, some expansion of the pattern of label may reflect the strengthening of existing, previously undetected inputs; however, none of the findings indicate topographic imprecision sufficient to produce the marked expansion of label we have found after amputation. 


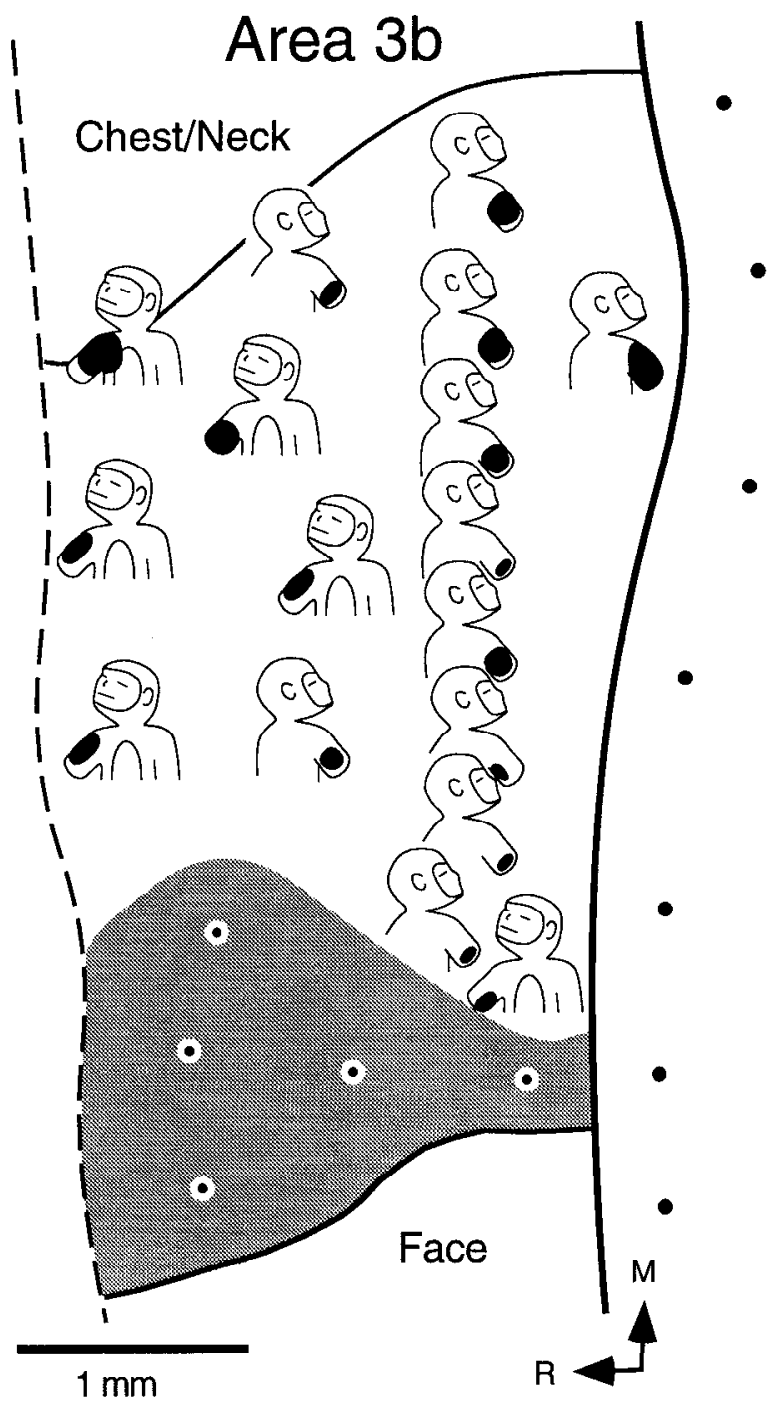

Figure 10. Dorsal view reconstruction of the topographic representation of the forelimb contralateral to amputation of the forearm in an adult owl monkey. Thick line depicts the caudal border of area $3 \mathrm{~b}$; the rostral border is dashed because its location is estimated. Within area $3 \mathrm{~b}$, solid lines demarcate the borders of the arm representation. Each recording site is indicated by a figurine of the torso of a monkey, with the receptive field at that site shown in black. The dots caudal to area $3 \mathrm{~b}$ depict recording sites where topographic reversals indicated that the electrode had crossed cortical borders. The stippled region indicates a zone where neurons were not activated by cutaneous stimulation. $M$, Medial; $R$, rostral.

A third possible explanation for the expansion of label after amputations, and the one that seems most compelling to us, is that the expanded zones of label reflect the growth of intact afferents into the deprived zones in the spinal cord and brainstem. The potential for new growth, or axonal sprouting, to contribute to adult plasticity has long been disputed. Liu and Chambers (1958) first reported in cats using the degeneration technique that intact sensory afferents would grow into territorics of the dorsal horn vacated by previously sectioned dorsal roots (see also Goldberger and Murray, 1974). However, subsequent studies failed to confirm the report (e.g., Rodin et al., 1983; Rodin and Kruger, 1984). Thus, the view that the mature somatosensory system does not form extensive new connections prevailed until only recently when sprouting has been unequivocally dem- onstrated in the adult somatosensory system (e.g., Molander et al., 1988; LaMotte et al., 1989; McMahan and Kett-White, 1991; Cameron et al., 1992; Woolf et al., 1992; Florence et al., 1993; Koerber et al., 1994) and in many other neural systems (Tsukahara et al., 1982; Darian-Smith and Gilbert, 1994; Li et al., 1994; Nitsch and Leranth, 1994). Given that the distribution of label after forelimb amputation is more extensive than can be accounted for by the strengthening of existing, but previously undetected inputs, the best interpretation for the results is sprouting of inputs from the remaining arm into deprived portions of the spinal cord and brainstem. Forelimb amputation in fetal rats also leads to an expansion of remaining dorsal column afferents into the deprived cuneate nucleus (Rhoades et al., 1993).

An uncertainty that remains is why sprouting occurs under some conditions and not others. Most notably, Rasmusson (1988) reported that digit amputation in raccoons has no effect on the distribution of afferent inputs to the dorsal column nuclci from the remaining digits. This indicates that small deactivations such as digit amputation, and large deactivations, such as hand or forearm amputation, have very different impacts on the potential for new growth. An important future direction for study is to discern factors that contribute to and limit sprouting in the adult nervous system.

It may seem surprising that the long-standing amputations did not cause a more significant modification of the structural organization of the spinal cord and cuneate nucleus. In the visual system, adult enucleation has a dramatic impact at all levels of primary visual pathway (e.g., Haseltine et al., 1979; Florence and Kaas, 1991). However, it appears that the somatosensory pathway is more adaptive, and the effect of sensory denervation depends on the age at which the manipulation is performed and the extent of the denervation. In general, sensory manipulations during embyonic or early postnatal development results in marked changes in the structural organization and density of histochemical staining of the sensory representations but have much less effect later in life (e.g., Belford and Killackey, 1980; Killackey and Belford, 1989; Chiaia et al., 1992; Foschini et al., 1994). In macaque monkeys, dorsal rhizotomy of the cervical ganglia related to the forelimb results in an overall reduction of the size of the cuneate nucleus, but no decrement in the staining of the remaining neurons for cytochrome oxidase or for the calcium binding protein, parvalbumin (Rausell et al., 1992). In the present cases, the preservation of structure and staining may be in part related to the expansion of activating inputs and perhaps to the retention of dorsal root ganglion cells related to the denervated skin.

\section{Effects of amputation on the organization of area $3 b$}

In all the monkeys, regardless of the level of amputation, the representation of the remaining forelimb skin expanded into the deprived hand representation. Since the overall size of the forelimb representations contralateral to the amputation were smaller than the forelimb representations in normal animals, there may also have been an expansion of the face representation into the lateral part of the deprived region in area $3 \mathrm{~b}$. Previously, largescalc cortical rcorganization has becn shown after a hand amputation in a raccoon (Rasmusson et al., 1985), and in macaque monkeys with long-standing deafferentation of the forelimb (Pons et al., 1991). In humans, noninvasive mapping techniques have been used recently to demonstrate cortical reorganization after hand or forearm amputation (Elbert et al., 1994; Yang et al., 1994; Flor et al., 1995). Such extensive reorganization has 
been seen as the basis for perceptual abnormalities, such as phantom limb sensations (Ramachandran et al., 1992; Ramachandran, 1993; Halligan et al., 1993). These more extensive cortical reactivations presumably occur over relatively long periods of time. In a study of the time course of cortical reorganization in adult cats, the extent of reactivated cortex progressively expanded for up to 1 year (the longest survival time included) after transection of all forelimb nerves (Dykes et al., 1995; see also Kalaska and Pomeranz, 1979).

In contrast to the above reports, most studies of denervationinduced plasticity in adult primates revealed a much more limited capacity for reorganization. For example, while amputation of a single digit is followed by rapid and complete cortical reorganization (Merzenich et al., 1984; Calford and Tweedale, 1991), at least some of the deprived cortex remains silent after amputation of two adjacent digits (Merzenich et al., 1984). Also after transection of peripheral nerves to both the palmar (glabrous) and hairy surfaces of the hand, to produce a type of denervation similar to digit amputation, much of the deprived cortex remains silent for up to 11 months after nerve transection (Garraghty et al., 1994). The basis for the somatotopic reorganization, in all these reports, is assumed to be the potentiation of existing, previously latent synaptic inputs. Furthermore, the limitations in the cxtent of the reactivations presumably reflect the minimal overlap of connections related to noncontiguous skin regions.

In only one instance has extensive cortical reorganization been attributed to potentiation of existing connections in primates. In this case, the entire glabrous hand was denervated by nerve section producing a large zone of deprived cortex in squirrel and owl monkeys, and over the course of months, deprived cortex came to be completely reactivated by the representation of the hairy skin of the hand (Garraghty and Kaas, 1991). This unusually large zone of cortical reorganization resulting from potentiation of existing connections reflects the normal distribution of primary afferent inputs from the hand in the spinal cord and cuneate nucleus. Inputs from adjacent hairy and glabrous surfaces of the hand overlap somewhat (Florence et al., 1991), so that target neurons can potentially be activated by either the glabrous or hairy skin. In contrast, inputs from adjacent regions of the glabrous surfaces of the hand (i.e., adjacent digits) terminate in cell clusters that are separated from one another by fibers. Thus, when both glabrous and hairy skin surfaces are denervated, such as after amputation, the potential for existing connections to contribute to reorganization is limited. In order to produce extensive cortical changes, such as in the present report, additional mechanisms would seem to be required.

The most significant contribution of the present study is the demonstration that the mechanism that produces large-scale functional reorganization in cortex may be sprouting of intact sensory afferents in the brainstem or spinal cord. Some sprouting and reinnervation also might occur in the thalamus, but the changes observed in the brainstem alone could account for most of the cortical reorganization in the present cases. The spatially limited changes in primary afferents in the brainstem likely are magnified enormously in the relay to primary somatosensory. We hypothesize that the same mechanism can account for the complete reactivation of forearm cortex in area $3 b$ by the face representation following deafferentation of the forelimb produced by dorsal rhizotomy (Pons et al., 1991). As with amputation, the extensive deprivation produced by the dorsal rhizot- omies would be a sufficient stimulus to induce sprouting into the cuneate nucleus by the large number of afferents from the face that normally terminate in the adjacent trigeminal complex. Such sprouting may have occured in the present cases, but injections were not placed in the skin of the face to examine this possibility.

Our results have exciting and clinically relevant implications for further studies of adult plasticity. If sprouting of neural elements is possible in the mature nervous system, we need to determine what factors allow and promote such growth. Furthermore, while the cortical reactivations described here may have no apparent functional benefit, and likely produce functional distraction and impairment, they help provide an understanding of clinical situations where patients detect phantom sensations and often suffer pain (Melzack, 1990). More importantly, perhaps, is the possibility that these results will lead to insights into the mechanisms that produce functional recovery after damage to the CNS.

\section{References}

Bakker DA, Richmond FJR, Abrahams VC, Courville J (1985) Patterns of primary afferent termination in the external cuneate nucleus from cervical axial muscles in the cat. J Comp Neurol 241:467-479.

Bausbam AI, Wall PD (1976) Chronic changes in the response of cells in adult cat dorsal horn following partial deafferentation: the appearance of responding cells in a previously non-responsive region. Brain Res 116:181-204.

Belford GR, Killackey HP (1980) The sensitive period in the development of the trigeminal system of the neonatal rat. J Comp Neurol 193:335-350.

Brown AG (1981) The primary afferent input: some basic principles. In: Spinal cord sensation (Brown AG, Rethelyi M, eds). Edinburgh: Scottish Academic.

Brown AG, Fyffe REW, Noble R, Rowe MJ (1984) Effects of hind limb nerve section on lumbrosacral dorsal horn neurones in the cat. J Physiol (Lond) 354:375-394.

Brown PB, Brushart TM, Ritz LA (1989) Somatotopy of digital nerve projections to the dorsal horn in the monkey. Somatosens Mot Res $6: 309-317$

Brown PB, Gladfelter WE, Culberson JC, Covalt-Dunning D, Sonty RV, Pubols LM, Millecchia RJ (1991) Somatotopic organization of single primary afferent axon projections to cat spinal cord dorsal horn. J Neurosci 11:298-309.

Calford MB, Tweedale R (1990) The capacity for reorganization in adult somatosensory cortex. In: Information processing in mammalian auditory and tactile systems, pp 221-236. New York: Liss.

Calford MB, Tweedale R (1991) Immediate expansion of receptive fields of neurons in area $3 \mathrm{~b}$ of macaque monkeys after digit denervation. Somatosens Mot Res 8:249-260.

Cameron AA, Pover CM, Willis WD, Coggeshall RE (1992) Evidence that fine primary afferent axons innervate a wider territory in the superficial dorsal horn following peripheral axotomy. Brain Res 575: 151-154.

Chiaia NL, Bennett-Clarke CA, Eck M, White A, Crissman, RS, Rhoades RW (1992) Evidence for prenatal competition among the central arbors of trigeminal primary afferent neurons. J Neurosci 12:62-76.

Culberson JL, Brushart TM (1989) Somatotopy of digital nerve projections to the cuneate nucleus in the monkey. Somatosens Mot Res $6: 319-330$

Darian-Smith C, Gilbert CK (1994) Axonal sprouting accompanies functional reorganization in adult cat striate cortex. Nature 368:737740.

Devor M (1983) Plasticity of spinal cord somatotopy in adult mammals: involvement of relatively ineffective synapses. Birth Defects: Original Article Series 19:287-314.

Devor M, Wall PD (1978) Reorganization of spinal cord sensory map after peripheral nerve injury. Nature 275:75-76.

Devor M, Wall PD (1981) Effect of peripheral nerve injury on receptive fields of cells in the cat spinal cord. J Comp Neurol 199:277291.

Dostrovsky JO, Millar J, Wall PD (1976) The immediate shift of af- 
ferent drive of dorsal column nucleus cells following deafferentation: a comparison of acute and chronic deafferentation in gracile nucleus and spinal cord. Exp Neurol 52:480-495.

Dykes RW, Avendano C, Leclerc SS (1995) Evolution of cortical responsiveness subsequent to multiple forelimb nerve transections: an electrophysiologcal study in adult cat somatosensory cortex. J Comp Neurol 354:333-344.

Elbert T, Flor H, Birbaumer N, Knecht S, Hampson S, Larbig W, Taub E (1994) Extensive reorganization of the somatosensory cortex in adult humans after nervous system injury. Neuroreport 5:2593-2597.

Flor H, Elbert T, Knecht S, Wienbruch C, Pantev C, Birbaumer N, Larbig W, Taub E (1995) Phantom-limb pain as a perceptual correlate of cortical reoganization following arm amputation. Nature 375 : $482-484$.

Florence SL, Kaas JH (1991) Ocular dominance columns in area 17 of Old World macaque and talapoin monkeys: complete reconstructions and quantitative analyses. Visual Neurosci 8:449-462.

Florence SL, Wall JT, Kaas JH (1989) Somatotopic organization of inputs from the hand to the spinal cord and cuneate nucleus of monkeys with observations on the cuneate nucleus of humans. J Comp Neurol 286:48-70.

Florence SL, Wall JT, Kaas JH (1991) Central projections from the skin of the hand in squirrel monkeys. J Comp Neurol 311:563-578.

Florence SL, Garraghty PE, Carlson M, Kaas JH (1993) Sprouting of peripheral nerve axons in the spinal cord of monkeys. Brain Res 601 : 343-348

Foschini DR, Egger MD, Crockett DP (1994) The mutability of lowaffinity nerve growth factor receptor ( $\mathrm{p} 75^{\mathrm{NGFR}}$ ) expression in the rat cuneate nucleus following perinatal injury and adult deafferentations: comparisons with cytochrome oxidase. Brain Res 646:1-12.

Garraghty PE, Kaas JH (1991) Large-scale functional reorganization in adult monkey cortex after peripheral nerve injury. Proc Natl Acad Sci USA 88:6976-6980.

Garraghty PE, Kaas JH (1992) Dynamic features of sensory and motor maps. Curr Opinion Neurobiol 2:522-527.

Garraghty PE, Hanes DP, Florence SL, Kaas JH (1994) Pattern of peripheral deafferentation predicts reoganizational limits in adult primate somatosensory cortex. Somatosens Mot Res 11:109-117.

Gibson AR, Hansma DI, Houk DC, Robinson FR (1984) A sensitive low artifact TMB procedure for the demonstration of WGA-HRP in the CNS. Brain Res 298:235-241.

Goldherger M, Murry M (1974) Restitution of function and collateral sprouting in cat spinal cord: the deafferented animal. J Comp Neurol 158:37-54.

Halligan PW, Marshall JC, Wade DT, Davey J, Morrison D (1993) Thumb in cheek? Sensory reorganization and perceptual plasticity after limb amputation. Neuroreport 4:233-236.

Haseltine EC, DeBruyn EJ, Casagrande VA (1979) Demonstration of ocular dominance columns in Nissl-stained sections of monkey visual cortex following enucleation. Brain Res 176:153-158.

Hummelsheim $\mathrm{H}$, Wiesendanger $\mathrm{R}$, Wiesendanger $M$, Bianchetti $M$ (1985) The projections of low-threshold muscle afferents of the forelimb to the main and external cuneate nuclei of the monkey. Neurosci 16:979-987.

Kaas JH (1991) Plasticity of sensory and motor maps in adult mammals. Annu Rev Neurosci 14:137-167.

Kaas JH, Pons TP (1988) The somatosensory system of primates. Comp Primate Biol 4:421-468.

Kalaska J, Pomeranz B (1979) Chronic paw denervation causes an agedependent appearance of novel responses from forearm in "paw cortex" of kittens and adult cats. J Neurophysiol 42:618-633.

Killackey HP (1989) Static and Dynamic aspects of cortical somatotopy: a critical evaluation. J Cognit Neurosci 1:3-11.

Killackey HP, Dawson DR (1989) Expansion of the central hindpaw representation following fetal forelimb removal in the rat. Eur J Neurosci 1:210-221.

Koerber HR, Mirnics K, Brown PB, Mendell LM (1994) Central sprouting and functional plasticity of regenerated primary afferents. J Neurosci 14:3655-3671.

LaMotte CC, Kapadia SE, Kocol CM (1989) Deaferentation-induced expansion of saphenous terminal field labelling in the adult rat dorsal horn following pronase injection of the sciatic nerve. J Comp Neurol 288:311-325.

Li WWY, Yew DTW, Chuah MI, Leung PC, Tsang DSC (1994) Axonal sprouting in the hemisected adult rat spinal cord. Neuroscience 61: 133-139.

Liu CN, Chambers WW (1958) Intraspinal sprouting of dorsal root axons. Arch Neurol Psychiatry 79:46-61.

Lund JP, Sun GD, Lamarre Y (1994) Cortical reorganization and deafferentation in adult macaques. Science 265:546-548.

McMahon SB, Kett-White R (1991) Sprouting of peripheral regenerating primary sensory neurones in the adult central nervous system. J Comp Neurol 304:307-315.

Melzack R (1990) Phantom limbs and the concept of a neuromatrix. Trends Neurosci 13:888-892.

Merzenich MM, Kaas JH, Sur S, Lin C-S (1978) Double representation of the body surface within cytoarchitectonic areas $3 \mathrm{~b}$ and 1 in "SI" in the owl monkey (Aotus trivirgatus). J Comp Neurol 181:41-74.

Merzenich MM, Nelson RJ, Stryker MP, Cynader MS, Schoppmann A, Zook JM (1984) Somatosensory cortical map changes following digit amputation in adult monkeys. J Comp Neurol 224:591-605.

Meyers DER, Snow PJ (1984) Somatotopically inappropriate projections of single hair follicle afferent fibres to the cat spinal cord $\mathbf{J}$ Physiol (Lond) 347:59-73.

Millar J, Basbaum AI, Wall PD (1976) Restructuring of the somatotopic map and appearance of abnormal neuronal activity in the gracile nucleus after partial deafferentation. Exp Neurol 50:658-672.

Molander C, Kinnman E, Aldskogius H (1988) Expansion of spinal cord primary sensory afferent projection following combined sciatic nerve resection and saphenous nerve crush: a horseradish peroxdase study in the adult rat. J Comp Neurol 276:436-411.

Nelson RJ, Sur M, Felleman DJ, Kaas JH (1980) Representations of the body surface in postcentral parietal cortex of Macaca fascicularis. J Comp Neurol 192:611-643.

Nitsch R, Leranth C (1994) Sprouting of remianing substance P-immunoreactive fibers in the monkey dentate gyrus following denervation from its substance P-containing hypothalamic afferents. Exp Brain Res 100:522-526.

Nyberg G, Blomqvist A (1984) The central projection of muscle af ferent fibers to the lower medulla and upper spinal cord: an anatomical study in the cat with the transganglionic transport method. J Comp Neurol 230:99-109.

O'Leary DM, Ruff NL, Dyck RH (1994) Development, critical period plasticity, and adult reorganizations of mammalian somatosensory systems. Curr Opinion Neurobiol 4:535-544.

Pettit MJ, Schwark HD (1993) Receptive field reorganization in dorsal column nuclei during temporary denervation. Science 262:20542056.

Pons TP, Garraghty PE, Ommaya AK, Kaas JH, Taub E, Mishkin M (1991) Massive reorganization of the primary somatosensory cortex after peripheral sensory deafferentation. Science 252:1857-1860.

Pubols LM, Benowitz GL (1981) Alteration of dorsal horn function by acute and chronic deafferentation. In: Spinal cord sensation (Brown AG, Rethelyi M, eds). Edinburgh: Scottish Academic.

Ramachandran VS (1993) Behavioral and magnetoencephalographic correlates of plasticity in the adult human brain. Proc Natl Acad Sci USA 90:10413-10420.

Ramachandran VS, Rogers-Ramachandran D, Stewart M (1992) Perceptual correlates of massive cortical reorganization. Science 258: $1159-1160$

Rasmusson DD (1988) Projections of digit afferents to the cunetae nucleus in the raccoon before and after partial deafferentation. $\mathrm{J}$ Comp Neurol 277:549-556.

Rasmusson, DD, Turnbull BG, Leech CK (1985) Unexpected reorganization of somatosensory cortex in a raccoon with extensive forelimb loss. Neurosci Lett 55:167-172.

Rausell E, Cusick CG, Taub E, Jones EG (1992) Chronic deafferentation in monkeys differentially affects nociceptive and nonnociceptive pathways distinguished by specific calcium-binding proteins and down-regulates $\gamma$-aminobutyric acid A receptors at thalamic levels.

Rhoades RW, Wall JT, Chiaia NL, Bennett-Clarke C $\Lambda$, Killackey HP (1993) Anatomical and functional changes in the organization of the cuneate nucleus of adult rats after fetal forelimb amputation. $\mathbf{J}$ Neurosci 13:1106-1119.

Rodin BE, Kruger L (1984) Absence of evidence for intraspinal sprouting in dorsal root axons caudal to a partial spinal hemisection: a horseradish peroxidase study. Somatosens Res 2:171-192.

Rodin BE, Sampogna S, Kruger L (1983) An examination of intras- 
pinal sprouting in dorsal root axons with the tracer horseradish peroxidase. J Comp Neurol 215:187-198.

Shortland P, Woolf CJ, Fitzgerald M (1989) Morphology and somatotopic organization of the central terminals of hindlimb hair follicle afferents in the rat lumbar spinal cord. J Comp Neurol 289:416-433.

Snow PJ, Wilson P (1991) Plasticity in the somatosensory system of developing and mature mammals - the effects of injury to the central and peripheral nervous system. In: Progress in sensory physiology II (Ottoson, ed). New York: Springer.

Tsukahara N, Fujito Y, Oda Y, Maeda J (1982) Formation of functional synapses in adult cat red nucleus from the cerebrum following crossiinnervation of forelimb flexor and extensor nerves. I Appearance of new synaptic potentials. Exp Brain Res 45:1-12.

Wall PD (1977) The presence of ineffective synapses and the circum- stances which unmask them. Philos Trans R Soc Lond [Biol] 278: 361-372.

Weinberger NM (1995) Dynamic regulation of receptive firlds and maps in the adult sensory cortex. Annu Rev Neurosci 18:129-158.

Wilson P (1987) Absence of mediolateral reorganization of dorsal horn somatotopy after peripheral deafferentation in the cat. Exp Neurol 95:432-447.

Woolf CJ (1987) Central terminations of cutaneous mechanireceptive afferents in the rat lumbar spinal cord. J Comp Neurol 261:105-119.

Woolf CJ, Shortland P, Coggeshall RE (1992) Peripheral nerve injury triggers central sprouting of myelinated afferents. Nature 355:75-78.

Yang TT, Gallen CC, Ramachandran VS, Cobb S, Schwartz B, Bloom FE (1994) Non-invasive detection of cerebral plasticity in adult human somatosensory cortex. Neuroreport 5:701-704. 